\title{
Capital nacional e capital estrangeiro
}

\section{SAMUEL PINHEIRO GUIMARÃES}

InSTABILIDADE gerada pela desregulamentação dos mercados de
capitais, e os danos que teria trazido, e poderia trazer, para a eco-
nomia mundial, em especial para os países periféricos; e a possibilidade de disciplinar, em nível internacional, os movimentos de capitais privados, para diminuir sua volatilidade, orientá-los em direção à produção e reduzir sua vocação especulativa, são dois dos temas mais importantes do atual debate econômico.

Durante quatro anos o Brasil foi convencido de que, na era da globalização, o que valia era o capital, sua eficiência e sua competitividade, que a preocupação com o emprego, razão que deve ser suprema para todo governo, era antiquada e desnecessária, enquanto o Estado e a soberania seriam relíquias de um passado ruim. Na base de tudo, estaria agora o capital - sem pátria, abundante, progressista e capaz de tudo resolver - desde que fosse tratado sem distinções e que não se colocassem restrições aos seus movimentos.

Acreditando na igualdade de capitais, o Brasil promoveu radical desregulamentação de seus movimentos, inclusive privilegiando ostensivamente o capital estrangeiro. A desregulamentação foi acompanhada por política comercial de ampla abertura, caracterizada, do lado da importação, pela imprudência e, do lado da exportação, pela passividade, combinada com uma política de câmbio valorizado e de juros elevados. O resultado desse conjunto de políticas é a gravíssima crise externa latente de pagamentos em que hoje se debate o Brasil, com suas conseqüências internas: recessão, desemprego, violência e inquietação política.

Discutir o papel do capital estrangeiro e do capital nacional na economia brasileira, que se viu atingida subitamente pela volatilidade do capital, torna-se urgente porque as propostas de regulamentar, em nível internacional, os movimentos de capital, sem que antes tenha ocorrido crise de extraordinárias dimensões, não prosperam diante dos interesses dos países exportadores de capital, os quais têm sido afetados pela sua volatilidade de forma mais positiva do que negativa. 
Portanto, a disciplina dos movimentos de capital por taxas, como proposto por Tobin, ou pelo Fundo Monetário Internacional, tal como este existe ou reformado, advogada por economistas e políticos, em geral da periferia, não deverá ocorrer em tempo previsível pois os países que controlam de fato e de direito o FMI não parecem ter interesse maior em sua reforma, ou na imposição de disciplina aos seus próprios capitais.

Dessa forma, caso os países da periferia, ilusoriamente chamados de emergentes ou realisticamente de subdesenvolvidos, desejarem se defender dos gravíssimos riscos e danos para suas sociedades e Estados que a operação do sistema financeiro internacional, público e privado, pode trazer, devem procurar fazê-lo mediante políticas próprias, as quais devem partir da compreensão, cética e sóbria, da distinção entre capital nacional e capital estrangeiro, e dos efeitos deste último sobre a economia e a sociedade (1).

Neste artigo examinam-se as diferenças entre o capital de investimento direto estrangeiro e nacional, seus efeitos sobre a economia e as políticas de capital que serão cruciais para as perspectivas, no longo prazo, de desenvolvimento da sociedade e o lugar do Estado brasileiro na esfera internacional.

O capital estrangeiro hoje em dia corresponde, no caso dos investimentos e do comércio, a megaempresas multinacionais; no caso dos financiamentos, a megabancos; e no caso do capital especulativo, a megafundos de pensão. Em sua esmagadora maioria, essas megaentidades têm sede nos principais países desenvolvidos, que se encontram no centro do sistema econômico internacional e no centro das estruturas hegemônicas de poder.

A compreensão das relações entre capital estrangeiro e capital nacional, entre tecnologia e emprego, entre coesão social e violência, entre soberania e subordinação, entre centro e periferia é crucial para entender o processo de globalização - excludente e assimétrica - no qual está inserido o Brasil, e assim permitir a definição de políticas que façam com que a sociedade brasileira se beneficie de seus aspectos positivos e se defenda de seus efeitos negativos.

Todas essas questões estão profundamente interligadas e todas se relacionam com a formação dos mercados financeiros globais e com a política, impulsionada pelas megaempresas multinacionais e por seus respectivos governos, de forçar e consolidar a liberdade total para os movimentos de capitais, quer sejam eles especulativos, quer sejam de financiamento, quer sejam investimentos diretos (2).

As negociações na Organização Mundial do Comércio para a extensão do Acordo sobre Trims (3), as negociações da ALCA, as negociações na 
OCDE do AMI (4) e os planos de ajuste do FMI são todos movimentos táticos dentro de uma estratégia geral cuja finalidade é promover aquela liberdade, a qual beneficia essencial e logicamente os países com excedente de capital, e por conseguinte exportadores de capital, suas empresas, e a sua mão-de-obra.

Para que essa estratégia tenha sucesso é essencial que todos, as elites e a população em geral, nos países da periferia, estejam convencidos de que o capital estrangeiro e o capital nacional são igualmente benéficos para a economia e a sociedade locais, segundo argumentam a maioria dos economistas dos países exportadores de capital e seus discípulos na periferia.

Para alguns apologistas radicais, o capital estrangeiro seria até superior ao capital nacional pois aumentaria a poupança disponível para investimento, transferiria tecnologia, renovaria os métodos empresariais, aumentaria a concorrência e ampliaria o acesso da produção do país ao mercado internacional.

Não haveria assim razão para a legislação e a política discriminarem entre capitais e empresas segundo sua origem, mas até se deveria, quiçá, oferecer e dar a ele, ao estrangeiro, condições mais favoráveis do que ao capital local para, justamente, atraí-lo a investir diretamente em zonas de alto risco, como são os países da periferia, entre eles o Brasil.

Apesar de a insistência e a convicção com que esses argumentos são veiculados por economistas, políticos e pela mídia, a atual crise torna urgente examiná-los um a um, a partir da premissa de que a relação entre capital nacional e estrangeiro varia de acordo com a estrutura sócio-econômica do país e a etapa de desenvolvimento em que se encontra (5).

\section{Capital estrangeiro, poupança e formação de capital}

O capital nacional, em países subdesenvolvidos como o Brasil, tenderia a buscar, em geral, as oportunidades de investimento mais seguras e com retorno mais rápido. De seu lado, e verificando essa tendência, o Estado periférico ficaria sempre tentado a aumentar a carga tributária ou a dívida pública (interna e externa) ou a utilizar mecanismos inflacionários para financiar seus investimentos e assim alcançar uma taxa elevada de formação de capital. O capital estrangeiro permitiria aumentar o total de poupança disponível para investimento no país subdesenvolvido, inclusive em áreas nas quais detém a tecnologia mais avançada e tem experiência empresarial específica. O desenvolvimento nacional poderia assim ser acelerado com menor sacrifício e dificuldade política não só para a população em geral mas também para as elites econômicas. 
O bem-estar físico dos indivíduos na sociedade moderna decorre do volume e da qualidade dos bens que podem consumir e que têm de ser por eles adquiridos em função de sua renda, a qual pode provir de seu trabalho ou de transferências, privadas ou estatais. Desconsideradas as transferências, a capacidade de consumo de um indivíduo está diretamente ligada à sua capacidade produtiva e às estruturas de mercado que distribuem o resultado da produção entre trabalho e capital.

A capacidade produtiva, por sua vez, depende da formação do indivíduo e das máquinas e ferramentas lato sensu à sua disposição, enquanto a capacidade de produção da sociedade, como um todo, depende da quantidade e da qualidade da mão-de-obra e de seu estoque de capital, nele incluídos os recursos naturais (6).

A questão central que se coloca para o processo de desenvolvimento (entendido como criação de infra-estrutura básica, inclusive social, redução de desigualdades e preenchimento de lacunas nas cadeias produtivas) e de crescimento (aumento da produção) é a ampliação da capacidade instalada, isto é, do investimento em capital físico instalado e, portanto, da capacidade de produção, desde que tal ampliação corresponda ao aumento do número de postos de trabalho e à maior participação dos salários no resultado da produção.

Uma massa considerável de poupança para realizar esse investimento na ampliação da capacidade poderia vir da massa salarial ou do Estado pela tributação (ou pela inflação); porém, considerando o decréscimo gradual da massa de salários no total do produto, a grande parcela dos salários utilizada para consumo, devido ao baixo nível de renda per capita, e a resistência social à inflação como mecanismo para financiar investimentos, a maior massa de poupança para investimento terá de provir, nas áreas periféricas, da remuneração do capital, isto é, do lucro, mediante investimento privado ou da sua tributação para fins de investimento público.

É portanto a destinação do lucro (do excedente) em termos de poupança e de investimento na economia na qual ele foi gerado que permite estabelecer uma comparação entre a importância do papel da empresa privada nacional e o da empresa estrangeira, em uma economia periférica, como a brasileira.

As incertezas políticas e econômicas típicas de países da periferia em desenvolvimento fazem com que as empresas estrangeiras procurem ter a mais alta taxa de lucro a curto prazo para recuperar mais rapidamente o capital investido, e remeter a maior parcela de lucros ao exterior (7), após os investimentos indispensáveis à manutenção de sua faixa de mercado. 
Assim, do total da massa de excedente, de lucro gerado pelas atividades produtivas no país, disponível para poupança e investimento e portanto para ampliação da capacidade instalada, uma parte corresponde ao excedente gerado pelas empresas de capital estrangeiro e se destina à remuneração dos acionistas no exterior.

Ao contrário, a massa de recursos excedentes gerada pelas empresas nacionais está toda, em princípio, disponível para poupança e investimento no território nacional. Naturalmente, pode ocorrer evasão de capitais nacionais para o exterior, devido à debilidade ou à instabilidade da economia. Tal possibilidade, todavia, não afeta o raciocínio aqui desenvolvido.

A análise da origem dos recursos para investimento e ampliação da capacidade instalada revela que as empresas privadas financiam parte importante e às vezes até o total de seus investimentos com empréstimos junto a bancos, públicos ou privados, nacionais ou estrangeiros.

$\mathrm{O}$ investimento direto da empresa estrangeira se faz sob a forma de ingresso de capital de risco ou é financiado por empréstimos, internos ou externos. No caso do investimento financiado externamente, quer dê ele resultados positivos ou não, terão início a curto prazo remessas correspondentes a juros e principal, enquanto que no caso do investimento de risco as remessas se realizam a partir do momento em que há lucro.

À medida que as empresas estrangeiras no Brasil levantam recursos junto a bancos públicos ou privados brasileiros, isto é, mobilizam a poupança nacional para financiar seus investimentos, esta passa a contribuir para a remessa para o exterior de parte do total de lucros gerados na economia e, portanto, para a redução da taxa de expansão da capacidade instalada e do emprego no país.

No caso de financiamento de empresas estrangeiras pelo Estado periférico por meio de empréstimos ou isenções fiscais, o resultado é mais paradoxal pois o próprio Estado contribui para aumentar a transferência de excedente para o exterior e para a redução da taxa de ampliação da capacidade instalada no país.

\section{O capital estrangeiro e a mão-de-obra}

A empresa estrangeira seria superior à empresa nacional porque além de contribuir para expandir a demanda global por trabalho, aumentando a remuneração relativa desse fator, habilitaria e qualificaria a mão-de-obra nacional em tecnologias novas e remuneraria melhor a mão-de-obra que emprega. 
Ao realizar investimentos novos, a empresa estrangeira com capital próprio, originário do exterior, está criando ou expandindo a capacidade instalada de forma nova, mas não necessariamente ampliando a demanda global por mão-de-obra.

Muitas vezes, o resultado do investimento estrangeiro ocasiona uma redução da demanda global quando este investimento novo elimina empresa concorrente que utilizava tecnologia mais intensiva em mão-de-obra.

Quando o investimento direto estrangeiro se faz por meio de aquisição de empresa brasileira, a modernização de seus equipamentos pode conduzir à redução do emprego. Do mesmo modo, quando o investimento estrangeiro se faz para modernizar com tecnologia intensiva em capital instalações suas já existentes, a produção da empresa estrangeira pode continuar igual, porém utilizando menos trabalho e pagando uma massa salarial menor.

No processo recente de modernização periférica, o aumento da capacidade instalada ou a modernização de instalações existentes têm assim correspondido à diminuição do número de empregos para igual ou maior volume de produção, com a conseqüente maior remuneração do capital, redução da massa salarial, aumento da concentração de renda e lenta expansão do mercado consumidor interno.

Ao procurar alcançar a mais alta taxa de lucro em seus investimentos na periferia, pagando como salários menor parcela de suas receitas obtidas na área periférica, a filial da empresa estrangeira contribui para que a taxa global de lucro da empresa multinacional a que pertence seja alta o suficiente para que possa assim realizar taxa de lucro menor no país-sede e apesar disso continuar a remunerar seus acionistas de forma aceitável e, simultaneamente, manter salários elevados para seus operários e funcionários nas unidades em seu país-sede.

Finalmente, o argumento de que as empresas multinacionais pagam salários mais altos do que as empresas concorrentes locais deve ser examinado à luz da comparação entre a massa salarial total que pagam as empresas estrangeiras e as nacionais e suas respectivas receitas.

Caso a massa salarial paga pelas empresas estrangeiras for uma parcela menor de suas receitas, ainda que salários individuais para uma mesma função possam ser mais elevados, os efeitos da empresa estrangeira sobre o emprego, a massa salarial e a demanda global são menos positivos do que afirma o argumento. 


\section{A empresa estrangeira}

\section{e o desenvolvimento científico e tecnológico}

A empresa nacional, pela sua dimensão, pelo custo mais baixo da tecnologia importada, e pelo escasso apoio estatal à pesquisa privada, tende a investir pouco em pesquisa tecnológica enquanto o Estado periférico dedica, direta ou indiretamente, valores absolutos reduzidos, e que correspondem a pequena parcela dos recursos à sua disposição, a programas de ciência e tecnologia.

O veículo principal de transferência de tecnologia das economias avançadas para as sociedades periféricas seria assim o investimento direto estrangeiro. O conhecimento científico e tecnológico seria, como qualquer mercadoria, disponível no mercado, bastando pagar o seu preço para adquiri-lo, ou bastando atrair a empresa que o detém para fazer com que tal conhecimento se incorpore ao sistema econômico nacional. A atração de capitais estrangeiros permitiria a um país periférico, como o Brasil, evitar investimentos vultosos em ciência e tecnologia, "queimar etapas de desenvolvimento", e finalmente não "reinventar a roda", no dizer de economistas irônicos.

Sem dúvida, as grandes empresas multinacionais são as maiores investidoras privadas em programas de ciência e tecnologia, dos quais surgem as inovações que reduzem seus custos, criam novos produtos, geram lucros extraordinários e permitem sua acelerada expansão em nível mundial.

Essas atividades e investimentos encontram-se, todavia, concentrados em unidades de pesquisa em seus países de origem, ou em outros países desenvolvidos, por razões empresariais, entre elas realizar economias de escala na pesquisa, ter acesso a maior oferta de mão-de-obra altamente qualificada e situar-se em mercados maiores.

A escassez de investimentos em pesquisa nas áreas periféricas, como o Brasil, é constatada pelo pequeno registro de patentes, como resultado de pesquisa aqui realizada. Todavia, mesmo quando a pesquisa se realiza aqui, no caso da empresa estrangeira a patente será registrada em nome da companhia e sua utilização no Brasil, ou em qualquer país, gerará pagamentos e remessas para a sede da empresa, detentora da patente. Por outro lado, e corretamente, a filial da empresa estrangeira na periferia remete recursos para sua sede sob a forma de pagamentos pela prestação de assistência técnica e pelo uso de marcas e patentes.

Ademais, quando se vincula a fornecedores locais, a filial da megaempresa multinacional leva à adoção de um certo padrão tecnológico, de- 
vido a restrições naturais do processo produtivo, e aprofunda a dependência tecnológica. Finalmente, sempre que sua presença amortece e desestimula o esforço de desenvolvimento tecnológico no sistema econômico local, a empresa estrangeira desestimula a formação de uma indústria local de bens de capital, a qual é essencial ao progresso tecnológico autônomo, único capaz de tornar a empresa local competitiva de forma permanente no mercado internacional.

A companhia de capital estrangeiro tende a reservar os cargos de direção em suas filiais no exterior a executivos e funcionários estrangeiros, inclusive como forma de preservar segredos industriais e evitar que a tecnologia vaze, isto é, realmente se transfira e venha a ser utilizada por empresas concorrentes locais ou estrangeiras.

Outro argumento sobre a transferência de tecnologia é que ela ocorreria pelo mercado, ou seja, pelo acesso do consumidor a produtos antes desconhecidos ou de melhor qualidade. Em realidade, o fato de os consumidores terem acesso a tais produtos apenas aumenta a importação desses produtos e diminui a produção local, mas não significa que se realizarão investimentos novos no país para produzi-los, nem que empresários locais poderão licenciar tais tecnologias ou desenvolvê-las no país. Esta visão sobre a transferência de tecnologia foi utilizada no Brasil como argumento adicional para justificar a abertura radical do comércio exterior como uma estratégia de modernização tecnológica da indústria brasileira.

Caso tivesse havido transferência significativa de tecnologia no Brasil após o enorme ingresso de capital estrangeiro que se verificou nas últimas décadas, teriam surgido empresas brasileiras que, tendo absorvido aquelas tecnologias, transferidas pelo capital estrangeiro, estariam hoje concorrendo com as empresas estrangeiras no mercado brasileiro e no mercado mundial, como ocorreu no caso do processo de expansão das empresas japonesas.

Em resumo, o mito de que o capital estrangeiro necessariamente transfere tecnologia reflete uma confusão conceitual entre o acesso do consumidor a produtos gerados por tecnologia avançada, ou a produção desses bens no território do país (com efeitos positivos sobre engenheiros e operários) e a efetiva transferência, isto é, a aquisição pela empresa e a mão-de-obra nacional com capacidade de produzir novos produtos. Tal confusão contribui para dificultar o esforço próprio de desenvolvimento científico e tecnológico, mantendo o país em um patamar tecnológico permanentemente inferior e, portanto, para que a economia permaneça menos competitiva; além de contribuir para um fluxo constante de pagamentos para o exterior e um déficit permanente no item tecnologia do balanço de transações correntes. 


\section{Capital estrangeiro, modernização empresarial e concorrência}

A principal vantagem das megaempresas multinacionais, em especial as norte-americanas, em sua competição com as demais empresas seria sua superior capacidade de organização das atividades empresariais. Ora, esta capacidade é escassa nos países subdesenvolvidos devido às suas menores experiência, diversificação empresarial e acumulação de capital. Assim, o capital e a empresa estrangeira contribuiriam para modernizar, pelo exemplo e pela difusão gradual, as práticas empresariais brasileiras e para tornar as empresas brasileiras mais competitivas e eficientes, interna e externamente.

Os mercados dos países periféricos subdesenvolvidos, e entre eles o Brasil, são reduzidos pela pequena população ou pelo seu baixo poder aquisitivo ou pela elevada concentração da renda. A pequena dimensão do mercado é, como ensinou Adam Smith, o principal obstáculo à divisão do trabalho, à especialização e ao aumento da produtividade e da acumulação de capital. Assim, os preços dos bens tendem a ser mais elevados (inclusive o preço do dinheiro), a competição restrita a pequeno número de empresas, sendo o consumidor explorado e as pressões inflacionárias permanentes. Os capitais e as empresas estrangeiras contribuiriam para aumentar a concorrência e reduzir os preços ou mantê-los estáveis, além de gerarem efeitos positivos sobre o emprego e os níveis salariais, ao melhorar a relação capital/trabalho em favor da mão-de-obra.

Ora, a empresa estrangeira é, em sua grande maioria, uma empresa multinacional de grande porte, e detém capacidade organizacional, tecnológica e financeira maior do que as empresas nacionais do mesmo setor, em país da periferia.

Portanto, a entrada da empresa estrangeira no mercado nacional do país periférico, pequeno em termos de poder aquisitivo, se, no primeiro momento, tende a aumentar a concorrência no segmento específico em que atua, tende a reduzi-la no momento seguinte, ao absorver ou eliminar a empresa nacional concorrente.

Por outro lado, após sua instalação, a empresa estrangeira, por sua dimensão e acesso ao mercado internacional, aumenta as barreiras à entrada no mercado em que atua. Ficam criadas as condições para o surgimento de estruturas oligopolísticas no mercado periférico e, portanto, para a geração e remessa de lucros extraordinários e diminuição da poupança disponível para ampliar a capacidade instalada. 
A idéia de que seria viável na periferia, para combater essas tendências, utilizar a redução de tarifas de importação, como instrumento de controle da formação de oligopólios e de aumento de preços, depende, para seu êxito, da capacidade do país de aumentar suas receitas de divisas de forma crescente e sustentada pela geração de superávites nos itens de transações correntes. A estratégia de financiar elevados déficits comerciais pela atração de capitais de curto prazo utilizando o câmbio sobrevalorizado e fixo e taxas de juros extraordinariamente altas está fadada, a médio prazo, ao fracasso, como ocorreu no Brasil, no início de 1999.

\section{A empresa estrangeira e a balança comercial}

A empresa periférica de capital local é, em geral, de pequena dimensão em termos internacionais e sua área de operação raramente se estende a outros mercados. Em contraste, as estrangeiras geralmente são empresas de grande porte, com grande experiência internacional, filiais em muitos países e canais estabelecidos de comercialização e distribuição de insumos e produtos. Assim, essas megaempresas multinacionais poderiam contribuir para a expansão dos mercados externos para a produção nacional, com todos os efeitos favoráveis sobre o grau de divisão do trabalho na economia, sobre o aproveitamento de economias de escala e sobre a expansão da receita cambial.

Todavia, na prática, a implantação da empresa estrangeira no país periférico acarreta com freqüência o aumento das importações de partes e insumos, em geral de seus fornecedores tradicionais no exterior, sejam eles a ela vinculados ou não, gerando assim dispêndios adicionais de divisas enquanto, muitas vezes, se desarticulam os produtores locais daquelas partes e insumos como ocorreu, entre outras, com a indústria de autopeças no Brasil.

Por outro lado, e de uma forma geral, em especial em países de amplo mercado interno como o Brasil, a empresa estrangeira, a partir de sua estratégia global de produção e vendas, se implanta para atender ao mercado interno e eventualmente a mercados nacionais, de dimensão menor, na mesma região e que por isto não justificam a instalação de unidades de produção. Dificilmente a empresa estrangeira irá orientar, nesse caso específico, a sua produção para a exportação e obviamente jamais para mercados que são abastecidos por unidades suas neles instaladas.

Por outro lado, uma parte crescente do comércio exterior brasileiro, em especial de manufaturados, é um comércio intrafirma, isto é, entre filial e matriz, e os preços que são declarados para as diversas finalidades cambiais e tributárias são preços escriturais e não preços de mercado. Portanto, as receitas de exportação (e o ingresso de divisas) se reduzem e as despesas de 
importação (e a cobrança de direitos aduaneiros) também se reduzem, artificialmente.

Assim, de forma geral, a empresa estrangeira tende a contribuir mais para o aumento das importações do que das exportações, colaborando de forma negativa para a balança comercial. O impacto da empresa estrangeira sobre o balanço de pagamentos tende a ser, ademais, globalmente negativo devido à tendência a resultados negativos não somente em sua balança comercial individual mas também em diversos outros itens do balanço de transações correntes, como juros, lucros, assistência técnica, transporte etc.

\section{Efeitos políticos do capital estrangeiro}

Tradicionalmente, um dos argumentos contrários não ao capital estrangeiro mas sim à desnacionalização excessiva da economia tem sido de acarretar a transferência para o exterior dos centros de decisão da atividade econômica, ou seja, as decisões de investimento, de exportação, de importação, de uso da tecnologia, de emprego passam a ser tomadas não apenas em função das características e da situação da sociedade onde atuam as filiais das megaempresas multinacionais mas também, e talvez principalmente, em função da estratégia global daquelas megaempresas.

Por outro lado, a capacidade do governo do país periférico de enfrentar, de orientar e de eventualmente estimular ou punir uma filial de megaempresa multinacional, apoiada por seu governo de grande potência, é muito inferior àquela de que dispõe o governo diante de empresas de capital nacional.

Considerando, como consideravam os principais teóricos do desenvolvimento econômico, que cabe ao Estado do país periférico, diante de suas extraordinárias disparidades e vulnerabilidades, um papel estratégico na integração da economia periférica, no preenchimento de seus vazios produtivos, no desenvolvimento e difusão de tecnologia, na expansão do emprego, essa transferência dos centros de decisão afeta consideravelmente a capacidade de cumprir tais funções e, portanto, retarda o ritmo de crescimento e aumenta o hiato entre o país periférico e os países avançados. $\mathrm{Na}$ turalmente, é possível acreditar que as forças de mercado, totalmente liberadas na era da globalização que hoje se verifica claramente ser assimétrica e excludente, poderiam melhor cumprir aquelas funções. Nada indica estar isto ocorrendo nos principais países subdesenvolvidos, chamados de emergentes, que se vêem submergidos em crises extraordinárias por justamente terem tentado, temerariamente, colocar em prática tal visão idealista e quase-religiosa do sistema econômico internacional. 
Outro aspecto, bem menos considerado do que o da transferência dos centros de decisão econômica diz respeito aos efeitos propriamente políticos da desnacionalização excessiva do sistema produtivo nacional.

Diversos setores do parque industrial brasileiro caracterizam-se pela presença maciça de empresas estrangeiras, sendo muitas delas filiais de megaempresas multinacionais. Os dirigentes dessas empresas são, em muitos casos, executivos estrangeiros que permanecem por períodos de tempo relativamente curtos no Brasil, no comando dessas empresas, em mais uma etapa intermediária no curso de sua carreira na megaempresa em que trabalham.

O conhecimento desses executivos sobre o Brasil tende naturalmente a ser recente e relativamente superficial e é explicável que alguns venham a se enclausurar em quistos, até devido às dificuldades de língua e às diferenças de costumes, situação essa que tende a reforçar os estereótipos sobre a sociedade brasileira, tão comuns em seus países de origem, mesmo entre aqueles setores mais informados e cultos.

Ora, o sistema político de qualquer país, para ser eficientemente representativo e legítimo, deve refletir, de forma transparente, os interesses e as aspirações dos diversos segmentos da população, quer sejam eles econômicos, religiosos ou profissionais.

Todavia, a dificuldade em se fazer presente nos processos legislativo e executivo por meio de representantes autênticos, já que cidadãos estrangeiros não podem ser eleitos, nem exercer cargos na estrutura do Executivo, faz com que as filiais de empresas estrangeiras tendam a privilegiar, como instrumento de defesa e promoção de seus interesses, as articulações burocráticas dos lobbies junto aos distintos Poderes enquanto o setor industrial, como um todo, fica deficientemente representado nas estruturas do Executivo ou Legislativo ou representado apenas de forma indireta e inadequada.

Assim, segmentos econômicos e sociais com menor participação no PIB do que a indústria, como a agricultura e certas atividades de serviços, entre eles educação, saúde e bancos, mas onde se verifica uma presença muito maior de empresas de capital nacional, tendem a ficar relativamente super-representados, e de forma mais autêntica, do que o setor industrial brasileiro.

O preconceito anti-industrial na sociedade e mesmo entre as elites políticas tende a se avolumar pela ausência de vínculos mais profundos e mais legítimos entre os principais executivos e líderes da indústria e as lideranças de outros setores da economia e da sociedade. Aquele desequilíbrio na representação dos setores econômicos no processo político de elabora- 
ção de normas e de execução de políticas públicas e esse preconceito antiindustrial trazem sérios prejuízos à sociedade.

\section{Políticas públicas}

\section{para o capital nacional e estrangeiro}

O capital estrangeiro trouxe, no passado, extraordinárias contribuições para o desenvolvimento da economia brasileira, em especial para sua transformação de economia agroexportadora rural em economia industrial urbana.

Essa contribuição do capital estrangeiro verificou-se nos mais diversos setores da economia: na construção da infra-estrutura de portos e ferrovias nas zonas do café; na expansão da malha rodoviária e da indústria automobilística, com financiamentos públicos e investimentos privados; na instalação das indústrias de bens de consumo; na participação significativa na instalação de indústrias de base vitais como a siderurgia de aços nãoplanos e, finalmente, na petroquímica e no setor de bens de capital.

A contribuição do capital estrangeiro para a formação da capacidade instalada no Brasil se, por um lado, historicamente correspondeu a uma pequena parcela do total investido na formação de capital, por outro teve, muitas vezes, uma importância estratégica, ao realizar investimentos que o capital nacional não poderia realizar, por não dispor de tecnologia, ou hesitava em realizar, pela dimensão do empreendimento.

Todavia, é preciso notar que, em diversos momentos da história da formação industrial brasileira, a ação do Estado, construindo as bases físicas para a atuação do capital privado nacional ou estrangeiro - tais como a infra-estrutura de energia e de comunicações -, ou implementando políticas regulatórias das atividades do capital, foi decisiva para superar estrangulamentos localizados ou para dotar a economia da base indispensável ao seu desenvolvimento continuado e ao alcance de níveis mais elevados de sofisticação e competitividade.

Não fora a ação pioneira dos investimentos estatais e hoje a economia brasileira não disporia da energia elétrica e do petróleo necessários a seu funcionamento; não fora a ação do Estado e a indústria de bens de capital não teria surgido; não fora a ação disciplinadora e estimuladora do Estado e não se teria diversificado de forma extraordinária o comércio exterior por meio da expansão das exportações industriais.

A contribuição do capital estrangeiro realizou-se assim no quadro de políticas ativas de estímulo, disciplina e orientação da ação do capital es- 
trangeiro e do capital nacional que se inseriam, por sua vez, em estratégias de desenvolvimento de amplo alcance e visão, cujo objetivo básico, mantido com tenacidade, foi a construção de uma estrutura produtiva industrial moderna no país.

A título de exemplo, a determinação de índices de conteúdo nacional (nacionalização) para a produção das empresas estrangeiras fez com que surgissem empresas fornecedoras nacionais ou estrangeiras instaladas no Brasil e acarretou o aperfeiçoamento tecnológico e a integração do parque produtivo, além de ter induzido a formação de engenheiros e técnicos nos mais diversos setores produtivos.

As políticas de estímulo à exportação e de vinculação da importação à exportação forçaram as megaempresas multinacionais a reestruturar seus esquemas de divisão internacional de mercados para abrir espaço para as exportações de suas unidades instaladas no Brasil e promover a geração de divisas.

A atual política de desregulamentação e de passividade do Estado face ao capital estrangeiro e de paradoxal desprezo pelo capital nacional tem contribuído fortemente para o agravamento da crise econômica interna e externa, que sucedeu subitamente a um período de ilusões primeiromundistas. Caso mantida essa visão e essa política, não será possível superar a fase de baixo crescimento e profunda recessão em que ingressamos e que se nos é apresentada como indispensável a uma retomada do desenvolvimento, sempre adiada e cada vez mais distante.

Para que o capital estrangeiro possa dar no futuro contribuições ainda mais extraordinárias ao desenvolvimento do país sua ação tem de voltar a ser disciplinada por uma legislação e políticas públicas que o orientem a setores prioritários e que fortaleçam o capital nacional, os empresários e as empresas brasileiras.

Uma política de capital depende da capacidade fiscal do Estado, tanto para arrecadar quanto para aplicar recursos de forma estratégica. Ora, a empresa de capital nacional é favorável, por definição e naturalmente, à redução dos tributos que sempre tende a considerar excessivos, pois reduzem seu lucro. A empresa estrangeira tem a mesma posição inclusive porque os serviços públicos locais, sustentados pelos tributos que recolhe, não beneficiam seus nacionais (que estão obviamente em outros países), nem os tributos contribuem para a defesa de seu país de origem, enquanto fortalecem o Estado que a empresa estrangeira vê como seu antagonista principal.

Assim, a megaempresa multinacional é contra a intervenção do Estado na economia, quer como regulador quer como empresário, já que o 
Estado é, na periferia, o único ente capaz de enfrentar seu extraordinário poder econômico, de assimilar sua tecnologia ou de induzir a sua transferência. Assim, a elaboração e a implantação de uma política de capitais contará com sua oposição, para a qual procurará o apoio do capital nacional, que sendo ideologicamente contra o Estado, corre o risco de não perceber em tempo hábil que sem a ajuda deste último desaparecerá frente à megaempresa multinacional, como está ocorrendo no Brasil.

A empresa nacional deverá ter um tratamento diferenciado e privilegiado, sempre que contribuir de forma significativa para a formação de capital no país. Por outro lado, o objetivo maior de acelerar a expansão da capacidade instalada deve motivar políticas que induzam as empresas estrangeiras a reinvestir parcelas maiores de seus lucros no país.

A política de capitais não pode, como tem ocorrido, contribuir para o enfraquecimento e desaparecimento do capital e da empresa brasileira nem privilegiar o capital estrangeiro, de uma forma inédita e excessiva, como revelam os contratos de instalação de novas megaempresas multinacionais na área automobilística.

Os compromissos internacionais, que foram sendo assumidos pelo Estado brasileiro em sua época de fascínio neoliberal, iniciada em 1990, é retomada com vigor em 1995 e vem até a crise de 1999, dificultam mas não impedem a definição e execução de uma política de investimentos e de disciplina do capital nacional e estrangeiro, como alguns argumentam para justificar a inércia do Estado e declarar inviável e impossível qualquer política industrial.

Esta política pode e deve ter como seus principais instrumentos a utilização do crédito público diferenciado, a redução e a isenção fiscal, como aliás foi feito na indústria automobilística, e as compras governamentais para aquelas empresas que

- reinvistam maiores parcelas de seus lucros na ampliação da capacidade produtiva;

- invistam em programas de pesquisa científica e tecnológica no Brasil;

- privilegiem a aquisição de partes e componentes de produtores instalados no Brasil;

- invistam em áreas/setores definidos como prioritários do ponto de vista social ou tecnológico ou ambiental;

- empreguem tecnologias eficientes intensivas em trabalho; 
- ingressem efetivamente em novos mercados externos;

- apresentem uma balança comercial positiva.

Algumas dessas políticas são aplicadas, de diversos modos e mediante diferentes instrumentos, em países altamente desenvolvidos, como mostram estudos recentes realizados pelo IEDI (Instituto de Estudos de Desenvolvimento Industrial) e pela OCDE. Para que venham a ser definidas e aplicadas no Brasil, necessário apenas se faz que a atual orientação de política econômica, idealista e ingênua, seja substituída por uma estratégia realista que tenha como fundamento a percepção de que o desenvolvimento brasileiro, em um mundo conturbado de globalização assimétrica, deverá ter como sua base a indústria, o esforço científico e tecnológico e a redução gradual de sua vulnerabilidade externa, e nunca uma eterna e utópica ambição de especialização em agricultura e em indústrias de tecnologia conhecida e simples.

\section{Nota final sobre a próxima investida para a desestruturação periférica}

Durante a Rodada Uruguai, as agências econômicas internacionais e os governos dos países altamente industrializados desenvolveram ampla campanha de persuasão política junto às populações e aos governos subdesenvolvidos de que aquelas negociações eram vitais para os interesses desses últimos. A redução de tarifas e a eliminação de barreiras não-tarifárias permitiriam a expansão extraordinária de suas exportações, em especial de produtos agrícolas e primários em geral; a criação da OMC eliminaria o unilateralismo das retaliações arbitrárias norte-americanas; as novas regras sobre propriedade intelectual estimulariam o desenvolvimento e a transferência de tecnologia na periferia.

Infelizmente e, aliás, como deveria ser de se esperar, os resultados concretos, objetivos, são que aumentaram em muito, isto sim, as exportações dos países desenvolvidos e as nossas importações; e assim, em vez de grande exportador agrícola, o Brasil se tornou um dos maiores importadores mundiais de produtos agrícolas. As novas regras de propriedade intelectual em nada estimularam a geração ou a transferência de tecnologia, enquanto que os pagamentos pelo uso de patentes, marcas etc. subiram vertiginosamente em favor de seus detentores, isto é, das empresas estrangeiras. O unilateralismo e as pressões norte-americanas permaneceram em uma realidade que não se deixaria intimidar por uma organização - a OMC que os próprios Estados Unidos permitiram surgir. 
Agora, quando se inicia a campanha ideológica que prepara a chamada Rodada do Milênio da OMC, surgem os mesmos argumentos de que a eliminação dos obstáculos à exportação de produtos agrícolas, em especial na União Européia, permitirá que o Brasil se torne um grande exportador de produtos agropecuários e que, por tal razão, deve o Brasil participar de forma positiva daquelas negociações. Assim, na visão idealista e ingênua, o Brasil continua a almejar uma integração na economia mundial de forma arcaica e prejudicial aos interesses e às necessidades de economia do país, devido às características dos mercados internacionais de produtos primários, cujos preços, como hoje o FMI reconhece, não somente sofrem flutuações excessivas e desestabilizadoras, como apresentam tendência secular à baixa, com a conseqüente deterioração dos termos de intercâmbio. A estratégia de desenvolvimento e de inserção internacional que tem como fundamento a agricultura e mesmo o agribusiness sofisticado é insuficiente para que o Brasil desenvolva suas potencialidades econômicas e políticas.

Essa Rodada do Milênio, do ângulo de seus promotores altamente desenvolvidos, visa a desregulamentar (e a consolidar juridicamente essa desregulamentação) as atividades econômicas na periferia com o objetivo de impedir que os grandes Estados periféricos executem políticas ativas de desenvolvimento. A Rodada do Milênio é apenas uma vertente de uma ampla estratégia desenvolvida pelos Estados Unidos, em vários níveis - multilate$\mathrm{ral} /$ bilateral/ unilateral - em seu esforço de organização da economia mundial, permanecendo em seu centro, com os privilégios que lhe confere sua liderança das estruturas hegemônicas de poder.

\section{Notas}

1 No que diz respeito ao capital estrangeiro especulativo, a discussão poderia se limitar à idéia de jamais sustentar qualquer política de desenvolvimento sobre a atração de tais capitais e que, para evitar os resultados perniciosos de sua ação, seria suficiente taxar sua permanência no país de modo a, tanto quanto possível, evitar sua presença no sistema econômico. Países de política econômica conservadora, como o Chile, já o fazem há tempo e portanto essa taxação não representaria novidade, nem atrairia antagonismo insuperável. O Brasil, na década de 70, adotou tal medida. A procura por financiamento externo pelas empresas, estimulada pelo diferencial elevado entre as taxas de juros internas e externas, deveria ser regulada e limitada às operações que visam à geração de receitas em dólares, e obedecido um limite global para o endividamento privado no exterior. 
2 A política de liberalização dos mercados de capital é parte da estratégica política e econômica de reincorporar ao sistema capitalista global as antigas áreas socialistas e as áreas da periferia subdesenvolvida que haviam conseguido implantar estruturas industriais relativamente avançadas, e detinham certa autonomia diante dos interesses das megaempresas multinacionais.

3 TRIMS: Trade Related Investment Measures (Medidas Relativas a Investimentos que afetam o Comércio).

4 AMI: Acordo Multilateral sobre Investimentos.

5 Assim, a relação entre capital e trabalho e entre capital estrangeiro e nacional e as políticas que devem ser adotadas têm de ser distintas entre países altamente desenvolvidos, onde o crescimento da população (e da força de trabalho) é muito lento, e países subdesenvolvidos, como o Brasil, onde anualmente ingressam no mercado de trabalho cerca de 1,5 milhões de pessoas.

6 A idéia de que a educação, por si só, pode melhorar o nível de renda dos indivíduos e da sociedade como um todo e, portanto, seu bem-estar econômico ou que vai contribuir, por si só, para o aumento da produção é um equívoco. O processo educacional tem três objetivos: o primeiro, contribuir para o aperfeiçoamento cultural, espiritual e intelectual do indivíduo, de forma a que possa desenvolver plenamente suas potencialidades, usufruir melhor de sua natureza humana e contribuir para o progresso de sua sociedade e da humanidade; o segundo, formar um cidadão, capaz de participar da sociedade e de seu governo; e o terceiro é formar um indivíduo produtor de bens para o sistema econômico. No caso deste ensaio, estamos tratando apenas do último objetivo da educação, que é o menos importante: a formação do indivíduo como produtor de bens. Na ausência de bens de capital em quantidade e qualidade suficientes com os quais combinar o seu esforço, a melhor educação (econômica) dos indivíduos, ao aumentar a oferta de trabalho qualificado, reduzirá (ou manterá) os salários em cada segmento do mercado, mas aumentando a produtividade aumentará a produção e os lucros.

7 Os acionistas das grandes empresas de capital estrangeiro encontram-se no exterior, já que suas filiais nas áreas periféricas são, em geral, empresas de capital fechado, isto é, sem acionistas locais. Uma prática das empresas multinacionais que deve ser mencionada é a alocação contábil de lucros à jurisdição onde são menores as alíquotas de imposto de renda, o que provoca resultados negativos sobre a arrecadação tributária.

Samuel Pinheiro Guimarães é diretor do Instituto de Pesquisa de Relações Internacionais do Itamaraty (DF). 